\title{
Predation by Anthocoris minki pistaciae Wagner (Hemiptera: Anthocoridae) on Agonoscena pistaciae Burckhardt and Lauterer (Hemiptera: Psyllidae) at different temperatures
}

\author{
Mahshid Sarnevesht ${ }^{1}$, Mehdi Gheibi ${ }^{1 *}$ (D, Shahram Hesami ${ }^{1}$ and Hadi Zohdi ${ }^{2}$
}

\begin{abstract}
Pistachio is one of the most common tree nuts in Iran and in the world, and Agonoscena pistaciae Burckhardt and Lauterer (Hemiptera: Psyllidae) is propounded as a considerable pest of pistachio trees. Among the numerous predators, Anthocoris minki pistaciae Wagner (Hemiptera: Anthocoridae) was found as a common species in pistachio orchards of Kerman Province, Iran. The consumption rate index is essential to determine the prey-predator interaction and efficiency for biological control. On the other hand, temperature as an abiotic environmental factor has an important influence on population parameters of insects. Thus, predation rate of $A$. minki pistaciae feeding on A. pistaciae was evaluated at three different temperatures $(17,26$, and $30 \pm 2{ }^{\circ} \mathrm{C}$ ) with a $16 \mathrm{~L}: 8 \mathrm{D}$ photoperiod and $55 \pm 5 \% \mathrm{R} . \mathrm{H}$. All of the data were analyzed by the age-stage, two-sex consumption rate, MS Chart software (Ver. 2017.05.28). Obtained results showed that the highest net predation rate $\left(C_{0}\right)$ and the transformation rate from prey population to predator offspring $\left(Q_{p}\right)$ occurred at $30{ }^{\circ} \mathrm{C}(1309.13$ and 54.67 prey nymphs, respectively). Moreover, the highest value for the mean prey consumption of adult insects was (1300.15 psyllid nymphs) and the highest daily mean consumption rate was calculated at this temperature. Thereupon, $30^{\circ} \mathrm{C}$ is the best temperature for feeding A. minki pistaciae under the laboratory conditions.
\end{abstract}

Keywords: Agonoscena pistaciae, Anthocoris minki pistaciae, Prey consumption, Temperature

\section{Background}

Pistachio is globally valuable due to its nutritional value, economic significance, and important role in health (Kashaninejad and Tabil 2011). Kerman Province (in the southern part of Iran) is the largest pistachioproducing area in Iran (FAO 2016). The specific climatic conditions for the cultivation of pistachio (such as wilderness and dry areas with long and hot summers, cold winters, and low-quality soil, and salted water) have resulted in the spread of pests in pistachio orchards (Hosseinifard et al. 2008). Many phytophagous

\footnotetext{
* Correspondence: mehgheibi@yahoo.com

${ }^{1}$ Department of Entomology, Faculty of Agricultural Sciences, Shiraz Branch, Islamic Azad University, Shiraz, Islamic Republic of Iran

Full list of author information is available at the end of the article
}

(herbivore) arthropod pests attack pistachio trees, causing considerable damages to the crop (Zohdi et al. 2015). Among these pests, the common pistachio psyllid (CPP), Agonoscena pistaciae Burckhardt and Lauterer (Psyllidae), is the most adverse pest which was first reported on pistachio trees in Iran by Kiriukhin (1946) (Mehrnejad 2001).

Both nymphs and adults of CPP suck the leaves' sap and produce large amounts of dried and crystallized honeydew. Their damage to the plant leads to the fall of leaves, buds, and fruits which finally leads to yield reduction (Alizadeh et al. 2011). This pest produces several generations each year and is generally inhibited by applying chemical insecticides belonging to various classes multiple times per year (Hassani 2009). The use of insecticides failed to prevent the outbreak of this pest, and 
frequent use of these compounds has led to the development of pesticide resistance (CPP resistance occurs due to its high reproductive capacity and short life cycle) (Alizadeh et al. 2011). Due to such problems, integrated pest management (IPM) programs, especially biological control, are considered a suitable approach for controlling CPP (Mehrnejad 2001).

Some species of anthocorids including Anthocoris nemorum (L.), A. nemoralis (Fabricius), Orius vicinus (Ribaut), O. minutus (L.), and O. majusculus Reuter (Hemiptera: Anthocoridae) can effectively control psyllid species in infested pear orchards (Sigsgaard et al. 2006). Souliotis et al. (2002) reported A. nemoralis as a successful bio-control agent of CPP in Greece. Few studies have been found on its potential in pistachio orchards of Iran (Linnavuori and Hosseini 2000). Some aphid and psyllid species including Forda sp. (Hemiptera: Aphidoidea), Slavum sp. (Hemiptera: Aphidoidea), and Psyllopsis fraxini (L.) (Hemiptera: Psyllidae) have been recorded as preys of $A$. minki pistaciae (Falamarzi et al. 2009). Pourali et al. (2010) reported $A$. minki pistaciae as a well-known predator of $A$. pistaciae in pistachio orchards in Iran.

Anthocoris minki pistaciae is found from April to October in pistachio orchards in Kerman Province, Iran. Nowadays, the population of this predator in pistachio orchards (may be due to the use of large amounts of insecticides) is limited (Mehrnejad 2010; Yanik and Unlu 2011).

Among the known factors that influence the capacity of predators to consume prey is the temperature, as it affects the rate of growth, development, prey consumption, behavior, life cycles, population dynamics, and geographical distribution of insects (Islam and Chapman 2001). Rajabi (2004) reported that temperature increases boost metabolic interactions and then heighten the need for nutrition. So, before using biological control agents in new areas, it is necessary to know the thermal requirements of the agent (Pilkington and Hoddle 2006).

Previous studies showed benefits of using the age-stage, two-sex life table in food consumption of insect predators (Atlihan and Chi 2008).

The main purpose of this study was to investigate the influence of different temperatures on the predation rate of A. minki pistaciae when feeding on A. pistaciae as prey during immature and adult stages under laboratory conditions.

\section{Materials and methods}

\section{Predator's collection}

Samples of the anthocorids were collected from the wild and cultivated pistachio trees located in Kerman Province, Iran (Sirjan and Rafsanjan orchards, between $53^{\circ}$ $26^{\prime} \mathrm{E}$ and $25^{\circ} 55^{\prime} \mathrm{N}$ and $59^{\circ} 29^{\prime} \mathrm{E}$ and $32^{\circ} \mathrm{N}$ ) by using sweeping nets and aspirator, during May 2016. Collected bugs were transferred to the laboratory of Kerman Agricultural and Natural Resources Education and Research
Center and identified by the taxonomical keys of Linnavuori and Hosseini (2000) and Falamarzi et al. (2009), then A. minki pistaciae individuals were separated.

\section{Insect rearing}

Adult insects of the bugs were kept in a growth chamber at $25 \pm 1{ }^{\circ} \mathrm{C}, 55 \pm 5 \%$ R.H., and a photoperiod of $16 \mathrm{~h}: 8 \mathrm{~h}$ (L:D). They were fed on psyllids. In order to rear this predatory bug, the Leaf-disk method was used (Mehrnejad 1998). In this method, to retain the moisture and to keep the pistachio leaves healthy, the Petri dishes were filled with 5-mm-thick layer of $8 \%$ Agar gel, and one healthy and clean pistachio leaf was cut to the size of the Petri dish diameter $(52 \mathrm{~mm})$ and the back of the leaf was placed on Agar gel in each Petri-dish, then placed into the plastic box $(25 \mathrm{~cm} \times 20 \mathrm{~cm} \times 10 \mathrm{~cm})$. A ventilation hole $(0.2 \mathrm{~mm}$ and $3 \mathrm{~cm}$ diameter) was made in the middle of the lids of the Petri dish and box, respectively. Then it was covered by 50 mesh nets, and the relative humidity was controlled by placing saturated magnesium nitrate salt inside the box. The nymph and adult predators were fed on the nymphs of $A$. pistaciae, which were collected daily from the pistachio orchards.

\section{Predation rate of $A$. minki pistaciae during immature stages}

In order to determine the predation capacity of $A$. minki pistaciae during the nymphal stage, the food consumption of all nymphal instars was investigated in a pre-test separately. According to the results of the pre-test, the food consumption of the bugs was 50 CPPs (fourth instar nymphs). In the main test, newly emerged nymphs of 3 h-old $A$. minki pistaciae (first instar nymphs) were released individually on a Leaf-disk, and each individual was provided by $50 \mathrm{CPPs}$ (fourth instar nymphs). Leaf-disks were checked daily, the number of consumed and alive psyllids was recorded, and the nymphs of the bug were moved to a new Leaf-disk containing nymphs of CPP. The experiments were continued for second, third, fourth, and fifth nymphal instars until the nymphs reached adult stage. Molting status, survival rate, and developmental durations of predator nymphs (the five nymphal instars) were recorded daily to determine the time spent in each nymphal stage.

In order to determine the total amount of consumed prey, this experiment was carried out with 15 replications, and the amount of consumed prey was recorded daily from the first nymphal instar to the adult stage of this predator. These experiments were performed at three constant temperatures $\left(17,26\right.$, and $\left.30 \pm 2{ }^{\circ} \mathrm{C}\right)$, relative humidity $(55 \pm 5 \%)$, and photoperiods of $16 \mathrm{~L}: 8 \mathrm{D}$.

\section{Predation rate of $A$. minki pistaciae during adult stage}

After the adult emergence, the male and female individuals aged less than 1 day (0-24 h-old) were allowed to mate and 
then transferred to experimental Leaf-disks as described earlier. According to the results of the pre-test, the food consumption of adults in each Petri dish was estimated to be 200 CPPs (100 nymphs of the fourth nymphal stage of CPP for each bug) before the main experiment. The number of the consumed psylla and the laid eggs were counted daily until the death of adults; also, the survival rate and longevity of adults were calculated.

To determine the predation sex rate, the consumption rate of ten males was estimated under the same conditions, and to calculate the female daily consumption rate, the daily predation rate of males was subtracted from the average predation rate of the pairs. During the first week of the experiment, each dead male was replaced by an alive individual (Farhadi et al. 2011).

\section{Evaluation of predation rate}

In the age-stage, two-sex life table (Chi and Liu 1985), the age-specific survival rate $\left(l_{x}\right)$, and the age-specific fecundity $\left(m_{x}\right)$ for an individual of age $x$ are calculated as:

$$
\begin{aligned}
& l x=\sum_{j=1}^{\beta} s_{x j} \\
& m_{x}=\frac{\sum_{j=1}^{\beta} s_{x j} f_{x j}}{\sum_{j=1}^{\beta} s_{x j}}
\end{aligned}
$$

where $\beta$ is the number of life stages. The age-stage-specific survival rate $\left(s_{x j}\right)$ is the probability that a neonate survives to age $x$ and stage $j$, and the age-stage-specific fecundity $\left(f_{x j}\right)$ means the mean number of offspring produced by individual $A$. minki pistaciae of age $x$ and stage $j$ per day.

The age-specific predation rate $\left(k_{x}\right)$ is the mean number of the fourth nymphal instar of $A$. pistaciae consumed by $A$. minki pistaciae at age $x$ :

$$
k_{x}=\frac{\sum_{j=1}^{\beta} s_{x j} c_{x j}}{\sum_{j=1}^{\beta} s_{x j}}
$$

By using $s_{x j}$, the age-stage-specific net consumption rate $\left(q_{x}\right)$ gives the weighted number of $A$. pistaciae consumed by $A$. minki pistaciae of age $x$ and is calculated as:

$$
q_{x}=k_{x} l_{x}
$$

The net consumption rate $\left(C_{0}\right)$ is the total amount of A. pistaciae consumed by an average individual during its longevity. This parameter shows the predation capacity of a predator population (both sexes and all individuals that died before the adult stage), where $\delta$ is the last age of the population:

\begin{tabular}{|c|c|c|c|c|c|c|}
\hline \multirow[t]{2}{*}{ Developmental stage } & \multicolumn{2}{|c|}{$17^{\circ} \mathrm{C}$} & \multicolumn{2}{|c|}{$26^{\circ} \mathrm{C}$} & \multicolumn{2}{|c|}{$30^{\circ} \mathrm{C}$} \\
\hline & $N$ & Mean $\pm S E^{*}$ & $N$ & Mean \pm SE & $N$ & Mean \pm SE \\
\hline Egg & 15 & 0 & 15 & 0 & 15 & 0 \\
\hline $1^{\text {st }}$ nymphl instar & 15 & $14.6 \pm 0.46^{b}$ & 15 & $8.73 \pm 0.27^{c}$ & 15 & $15.07 \pm 0.21^{a}$ \\
\hline $2^{\text {nd }}$ nymphl instar & 14 & $22.57 \pm 0.44^{a}$ & 14 & $11.86 \pm 0.54^{c}$ & 14 & $20.57 \pm 0.4^{b}$ \\
\hline $3^{\text {rd }}$ nymphl instar & 14 & $38.64 \pm 0.69^{a}$ & 13 & $24.62 \pm 0.29^{c}$ & 13 & $35.15 \pm 0.27^{b}$ \\
\hline $4^{\text {th }}$ nymphl instar & 14 & $63.36 \pm 0.74^{a}$ & 13 & $39 \pm 0.45^{c}$ & 13 & $56.85 \pm 0.36^{b}$ \\
\hline $5^{\text {th }}$ nymphl instar & 14 & $80.21 \pm 4.96^{b_{* *}}$ & 13 & $91.69 \pm 1.01^{a}$ & 13 & $79.38 \pm 0.64^{b}$ \\
\hline Total nymphal stage & 15 & $205.73 \pm 14.34^{a}$ & 15 & $154.4 \pm 14.63^{c}$ & 15 & $182.8 \pm 16.64^{b}$ \\
\hline Adult male & 5 & $803.4 \pm 22.8^{b}$ & 4 & $839.75 \pm 95.26^{b}$ & 4 & $994.75 \pm 11.95^{a}$ \\
\hline Adult female & 9 & $1086 \pm 15.27^{c}$ & 9 & $1281.44 \pm 31.63^{b}$ & 9 & $1435.89 \pm 27.09^{a}$ \\
\hline Adult mean & 14 & $985.07 \pm 39.49^{c}$ & 13 & $1145.54 \pm 67.99^{b}$ & 13 & $1300.15 \pm 61.38^{a}$ \\
\hline Net predation rate $\left(C_{0}\right)$ & - & $1125.32 \pm 84.28^{b}$ & - & $1147.22 \pm 127.5^{b}$ & - & $1309.13 \pm 140.43^{a}$ \\
\hline Transformation rate $\left(Q_{p}\right)$ & - & $36.45 \pm 7.97^{b}$ & - & $39.05 \pm 7.1^{b}$ & - & $54.67 \pm 10.67^{a}$ \\
\hline
\end{tabular}

$$
C_{0}=\sum_{x=0}^{\partial} q_{x}=\sum_{x=0}^{\partial} k_{x} l_{x}=\sum_{x=0}^{\partial} \sum_{j=1}^{\beta} s_{x j} c_{x j}
$$

Table 1 Mean consumption capacity, $C_{0}$, and $Q_{p}$ of Anthocoris minki pistaciae fed on Agonoscena pistaciae at three different temperatures under laboratory conditions

Mean consumption capacity-mean number ( \pm SE) of nymphs of Agonoscena pistaciae eaten by different stage/sex of Anthocoris minki pistaciae; $C_{0}$ - the net predation rate; $Q_{p}$ - the transformation rate from prey population to predator offspring at three different temperatures $\left(17,26\right.$, and $\left.30{ }^{\circ} \mathrm{C}\right)$

*The SEs were estimated using 10,000 bootstraps and compared by Tukey's test (comparison of $95 \% \mathrm{Cl}$ )

**Within rows, values followed by the same letters do not significantly different.

$\mathrm{a}, \mathrm{b}, \mathrm{c}$ Represent quantities' numbers. ${ }^{\mathrm{a}}$ Shows the highest level of significance. 'Shows the lowest level of significance 

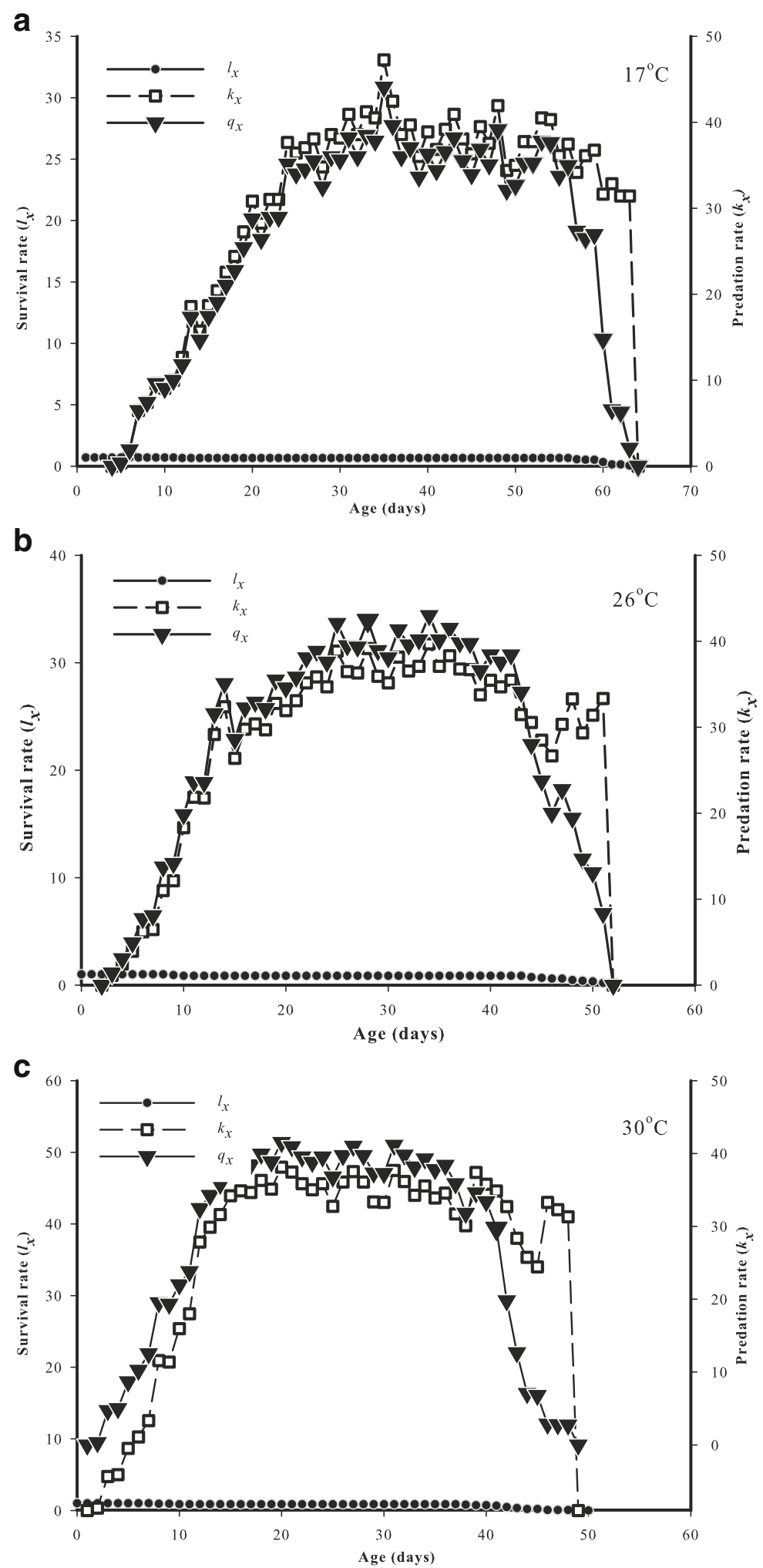

Fig. 1 Age-specific sunvival rate $\left(I_{x}\right)$, age-specific predation rate $\left(k_{x}\right)$, and age-stage-specific net predation rate $\left(q_{x}\right)$ of Anthocoris minki pistaciae fed with Agonoscena pistaciae at three different temperatures under laboratory conditions. $I_{x^{\prime}}$ the age-specific survival rate; $k_{x^{\prime}}$ the age-specific predation rate; and $q_{x^{\prime}}$ the age-stage-specific net predation rate $\left(I_{x} k_{x}\right)$ of Anthocoris minki pistaciae feeding on Agonoscena pistaciae nymphs at three different temperatures. a $17{ }^{\circ} \mathrm{C}$. b $26^{\circ} \mathrm{C}$. c $30^{\circ} \mathrm{C}$ 
The transformation rate from food mass to pest offspring $\left(Q_{p}\right)$ is the ratio of the net consumption rate to the net reproductive rate $\left(R_{0}\right) . Q_{p}$ gives the quantity of food needed for the production of an offspring and is calculated as:

$$
Q_{p}=\frac{C_{0}}{R_{0}}
$$

The age-stage-specific consumption rate $\left(c_{x j}\right)$ surveys the differentiation of stage and the variable predation rate among individuals. This item gives the average amount of $A$. pistaciae consumed by an individual of $A$. minki pistaciae of age $x$ and stage $j$ (Chi and Yang 2003).

\section{Data analysis}

The daily predation rate of 15 individuals was analyzed according to Chi and Yang (2003) by the age-stage, two-sex consumption rate, MS Chart software (Chi 2017) (Ver. 2017.05.28). The standard errors of the consumption parameters were also calculated, using both the bootstrap method $(n=10,000)$ and Tukey's test (0.05); also, the figures were drawn with Sigma Plot (Ver. 13.0, Systat software Inc.).

\section{Results and discussion}

This is the first research conducted to investigate the age-stage, two-sex predation rate of $A$. minki pistaciae.

The net predation rates $\left(C_{0}\right)$ of $A$. minki pistaciae at different temperatures are shown in Table 1 . The $\left(C_{0}\right)$ increased by increasing the temperature. At $30{ }^{\circ} \mathrm{C}$, it was significantly higher than those at 17 and $26{ }^{\circ} \mathrm{C}$. The $C_{0}$ was equal to the area under the curve of $l_{x} k_{x}$ (Fig. 1).

The transformation rates from the prey population to predator offspring $\left(Q_{p}\right)$ are shown in Table 1 . The $Q_{p}$ obtained a demographic estimation for the relationship between the reproduction rate and predation rate of the predator. A survey of the $Q_{p}$ indicated that the highest and lowest values were obtained at 30 and $17{ }^{\circ} \mathrm{C}$, respectively. This parameter increased significantly as temperature increased. In other words, A. minki pistaciae required 54.67 and 36.45 nymphs of CPP to produce a single egg at 30 and $17{ }^{\circ} \mathrm{C}$, respectively.

At three temperatures, the predation rate estimated was higher in adult stage compared with the immature stage. Food consumption rate of the female was significant at the three temperatures $(1086 \pm 15.27,1281.44 \pm$ 31.63 , and $1435.89 \pm 22.09$ nymphs) at 17,26 , and $30^{\circ} \mathrm{C}$, respectively. The results showed that the predation rate of females was higher than that of males. This difference could be due to the bigger size of females compared with the males, and the females need higher energy to lay eggs. Predation of adults gradually decreased with

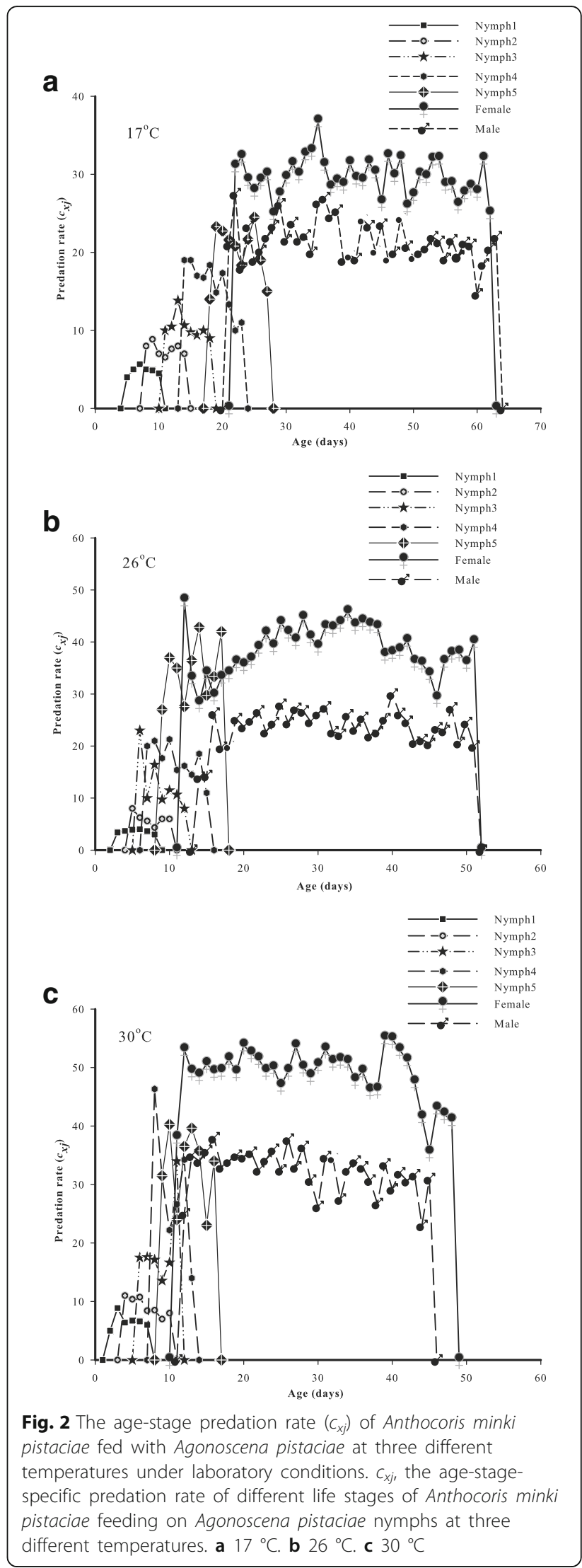


aging as well declined the number of eggs produced by females (Table 1).

The age-specific survival rate $\left(l_{x}\right)$, the age-specific predation rate $\left(k_{x}\right)$, and the age-stage-specific net consumption rate $\left(q_{x}\right)$ at different temperatures were illustrated in Fig. 1. The age-stage-specific net predation rate $\left(q_{x}\right)$ of the nymphs increased at first and then gradually decreased with the age-specific survival rate $\left(l_{x}\right)$. The highest $k_{x}$ and $q_{x}$ were observed at $30{ }^{\circ} \mathrm{C}$ on the 20th day, at $26^{\circ} \mathrm{C}$ on the 34 th day, and at $17{ }^{\circ} \mathrm{C}$ on the 20th day. However, the highest age-stage-specific net predation rate of male and female adults was recorded at $30^{\circ} \mathrm{C}$ (Fig. 1).

The age-stage-specific predation rate $\left(c_{x j}\right)$ of $A$. minki pistaciae on the fourth instar nymphs of CPP is shown in Fig. 2. This parameter stated the trend in age-stage-specific predation rate, i.e., the mean number of psyllids eaten by nymphs and adults of the predator of age $x$ and stage $j$. The daily consumption data for all individuals (males, females, and those died before reaching the adult stage) were used to calculate this item. The highest value for $c_{x j}$ is observed at $30^{\circ} \mathrm{C}$.

Obtained results showed that the temperature was effective on mean consumption capacity of the nymphal stage, and it increased by increasing temperature, but due to a longer nymphal period at $17{ }^{\circ} \mathrm{C}$ the highest mean numbers of eaten prey at this temperature. Then, this quantity increased as temperature raised from 26 to $30^{\circ} \mathrm{C}$.

The adults and all nymphal instars of $A$. minki pistaciae had the highest daily mean consumption rate of $\mathrm{CPP}$ at $30^{\circ} \mathrm{C}$ (Table 2).

Weighting coefficient showed the effect of different stages of predator life in controlling the prey's population quantitatively. If the weighting coefficient of adult females is one, the obtained weighting coefficients of adult males and fifth and fourth nymphal instars were $0.7,0.7$, and 0.5 , respectively (Table 2 ).

The present study showed that the predation rate of adults of $A$. minki pistaciae is closely associated with temperature rise. This result is in accordance with the results of the studies of Simonsen et al. (2009) and Zhang et al. (2012).

Among the nymphal stages, the fifth instar showed the highest food consumption at the three temperatures. This result was similar to those of Yanik and Unlu (2010). They reported that the food consumption of pre-adults of $A$. minki feeding on Ephestia kuehniella Zell. (Lepidoptera: Pyralidae) was affected by temperature, and the corresponding value was 123.1, 94.1, and 99.4 eggs at 20, 25, and $30{ }^{\circ} \mathrm{C}$, respectively. Obviously, this trend is similar to the results of immature stages in the present study.

At all temperatures tested, the prey consumption of adult females was more than that of males. Similar data has also been presented by Yanik and Unlu (2011) for $A$. minki feeding on A. pistaciae. Yanik and Unlu (2010) reported the highest prey consumption of females and males of A. minki fed with E. kuehniella egg was at $30{ }^{\circ} \mathrm{C}$ and 40\% R.H. (309.7 and 108.8, respectively). The contradiction between these data and the obtained results could be due to the difference in the nutritional quality of the hosts and experimental conditions. Yanik and Unlu (2011) stated that 631 and 303.5 nymphs of $A$. pistaciae were consumed by females and males of $A$. minki at $25 \pm 1{ }^{\circ} \mathrm{C}$. In the present study, this item for females and males of $A$. minki pistaciae was higher compared to the results of Yanik and Unlu (2011). This difference was due to the age of prey used in the test. Yanik and Ugur (2004) reported that the females of $A$. nemoralis consumed totally 1936 eggs of E. kuehniella at $25 \pm 1{ }^{\circ} \mathrm{C}$. The difference than obtained results may be pertained to the difference in types of prey.

\section{Conclusions}

The present study demonstrated that temperature affected the predation capacity of A. minki pistaciae. According to the results, despite the fact that $30{ }^{\circ} \mathrm{C}$ decreased longevity, it was the best temperature for

Table 2 Age-specific net consumption rate $\left(q_{x}\right)$, daily mean consumption rate, and weighting coefficient of Anthocoris minki pistaciae fed with Agonoscena pistaciae at three different temperatures under laboratory conditions

\begin{tabular}{|c|c|c|c|c|c|c|c|c|c|}
\hline \multirow{2}{*}{$\begin{array}{l}\text { Developmental } \\
\text { stage }\end{array}$} & \multicolumn{3}{|c|}{ Age-stage-specific net consumption rate $\left(q_{x}\right)$} & \multicolumn{3}{|c|}{ Daily mean consumption rate } & \multicolumn{3}{|c|}{ Weighting coefficient } \\
\hline & $17^{\circ} \mathrm{C}$ & $26^{\circ} \mathrm{C}$ & $30^{\circ} \mathrm{C}$ & $17^{\circ} \mathrm{C}$ & $26^{\circ} \mathrm{C}$ & $30^{\circ} \mathrm{C}$ & $17^{\circ} \mathrm{C}$ & $26^{\circ} \mathrm{C}$ & $30^{\circ} \mathrm{C}$ \\
\hline Egg & 0 & 0 & 0 & 0 & 0 & 0 & 0 & 0 & 0 \\
\hline $1^{\text {st }}$ nymphal instar & 14.6 & 8.73 & 15.06 & 5.09 & 3.74 & 7.06 & 0.17 & 0.09 & 0.14 \\
\hline $2^{\text {nd }}$ nymphal instar & 21.06 & 11.06 & 19.2 & 7.52 & 5.72 & 9.93 & 0.25 & 0.14 & 0.19 \\
\hline $3^{\text {rd }}$ nymphal instar & 36.06 & 21.33 & 30.46 & 11.04 & 12.31 & 17.58 & 0.37 & 0.31 & 0.35 \\
\hline $4^{\text {th }}$ nymphal instar & 59.13 & 33.8 & 49.26 & 16.74 & 17.48 & 29.56 & 0.56 & 0.44 & 0.59 \\
\hline $5^{\text {th }}$ nymphal instar & 74.86 & 79.46 & 68.8 & 21.19 & 35.06 & 35.59 & 0.71 & 0.89 & 0.71 \\
\hline Adult male & 267.8 & 223.93 & 265.26 & 21.71 & 23.99 & 32.88 & 0.73 & 0.61 & 0.65 \\
\hline Adult female & 651.6 & 768.86 & 861.53 & 29.71 & 39.09 & 49.9 & 1 & 1 & 1 \\
\hline
\end{tabular}

$q_{x}$-the age-stage-specific net consumption rate; daily mean consumption rate and weighting coefficient of different stage/sex of Anthocoris minki pistaciae feeding on the common pistachio psylla Agonoscena pistaciae at three different temperatures $\left(17,26\right.$, and $\left.30^{\circ} \mathrm{C}\right)$ 
feeding adults of $A$. minki pistaciae under the laboratory conditions because at this temperature, the highest net predation rate $\left(C_{0}\right)$ and the transformation rate from the prey population to predator offspring $\left(Q_{p}\right)(1309.13 \pm$ 140.3 and $54.67 \pm 10.67$ prey nymphs, respectively) were achieved. Moreover, the maximum mean prey consumption of adult insects $(1300.15 \pm 61.38$ psyllid nymphs $)$ was calculated at $30{ }^{\circ} \mathrm{C}$.

With regard to the climate and high temperature of Kerman Province, the predation activity of the main predators of CPP including ladybirds and lacewings decreases as temperature increases (Zohdi 2016). On the contrary, the obtained results may suggest that $A$. minki pistaciae can increase the population density and cause greater efficiency (under laboratory conditions) at $30{ }^{\circ} \mathrm{C}$ than at other temperatures tested in this study.

\section{Acknowledgements}

The authors are thankful to the Department of Plant Protection, Agriculture and Natural Resources Education and Research Center of Kerman for their help and support. The first author is grateful to the Agriculture Organization of Kerman for their cooperation in conducting this research.

\section{Availability of data and materials}

The datasets supporting the conclusions of this article are included within the article (and its additional files). Also "the datasets supporting the conclusions of this article are available in the Zenodo repository in https://zenodo.org/record/ 1217757\#.WtBPj2997Z5 and https://zenodo.org/record/1217761\#.WtBPrm997Z4

\section{Authors' contributions}

MS participated in the design of the study, conducted the experiments, prepared the manuscript, and performed the statistical study. MG and SH helped to improve this paper. $\mathrm{HZ}$, the consultant of this project, contributed to this study design. All authors read and approved the final manuscript.

\section{Ethics approval and consent to participate}

Not applicable.

\section{Consent for publication}

Not applicable.

\section{Competing interests}

The authors declare that they have no competing interests.

\section{Publisher's Note}

Springer Nature remains neutral with regard to jurisdictional claims in published maps and institutional affiliations.

\begin{abstract}
Author details
${ }^{1}$ Department of Entomology, Faculty of Agricultural Sciences, Shiraz Branch, Islamic Azad University, Shiraz, Islamic Republic of Iran. ²Plant Protection Research Department, Kerman Agricultural and Natural Resources Research and Education Center, Areeo, Kerman 7617913739, Islamic Republic of Iran.
\end{abstract}

Received: 13 April 2018 Accepted: 15 August 2018

Published online: 26 September 2018

\section{References}

Alizadeh A, Talebi K, Hosseininaveh V, Ghadamyari M (2011) Metabolic resistance mechanisms to phosalone in the common pistachio psyllid, Agonoscena pistaciae (Hemiptera: Psyllidae). Pestic Biochem Physiol 101:59-64. https://doi. org/10.1016/j.pestbp.2011.07.005

Atlihan R, Chi H (2008) Temperature-dependent development and demography of Scymnus subvillosus (Coleoptera: Coccinellidae) reared on Hyalopterus pruni (Homoptera: Aphididae). J Econ Entomol 101:325-333
Chi H (2017) CONSUME- MSChart: a computer program for consuming rate analysis based on the age stage, two-sex life table. http://140.120.197.173/ Ecology. Accessed 20 Jan 2017

Chi H, Liu H (1985) Two new methods for the study of insect population ecology. Bull Inst Zool Acad Sin 24:225-240

Chi H, Yang T (2003) Two-sex life table and predation rate of Propylaea japonica Thunberg (Coleoptera: Coccinellidae) fed on Myzus persicae (Sulzer) (Homoptera: Aphididae). Environ Entomol 32:327-333. https://doi.org/10. 1603/0046-225X-32.2.327

Falamarzi S, Asadi G, Hosseini R (2009) Species inventory, preys and host plants of Anthocoridae sensu lato (Hemiptera: Heteroptera) in Shiraz and its environs (Iran, Fars province). Acta Entomol Musei Nationalis Pragae 49(1):33-42

FAO (2016) Food and Agriculture Organization of the United Nations, FAOSTAT3: Core production data. http://www.Faostat3.fao.org. Accessed 17 May 2017

Farhadi R, Allahyari H, Chi H (2011) Life table and predation capacity of Hippodamia variegata (Coleoptera: Coccinellidae) feeding on Aphis fabae (Hemiptera: Aphididae). Biol Control 59(2):83-89. https://doi.org/10.1016/j. biocontrol.2011.07.013

Hassani MR (2009) Bioecology and economic injury level of Agonoscena pistaciae (Hemiptera: Psyllidae) in Rafsanjan region of Iran. Ph.D. Thesis, University of Islamic Azad, Tehran, p 105

Hosseinifard J, Salehi MH, Esfandiaripour I, Mohammadi J (2008) Spatial variability of groundwater quality and its relationship with pistachio yield in Anar region, Iran. Appl Sci 8(20):3697-3702

Islam SS, Chapman RB (2001) Effect of temperature on predation by Tasmanian lacewing larvae. Proceedings of the New Zealand plant protection conference. N Z Plant Prot Soc 54:244-247

Kashaninejad M, Tabil L (2011) Pistachio (Pistacia vera L.), postharvest biology and technology of tropical and subtropical fruits. Woodhead Publ Ser Food Sci Technol Nutr 4(11):218-246. https://doi.org/10.1533/9780857092618.218

Kiriukhin G (1946) Les insectes nuisibles au Pistacier en Iran. Ent Phytopath Appl 1:8-24

Linnavuori R, Hosseini R (2000) Heteroptera of Guilan with remark on species of the adjacent areas, 2nd edn. Guilan University Press, Rasht, p 95

Mehrnejad MR (1998) Evaluation of the parasitoid Psyllaephagus pistaciae (Hymenoptera: Encyrtidae) as a biological agent of the common pistachio psylla, Agonoscena pistaciae. Ph.D. Thesis, University of London, London, p 271

Mehrnejad MR (2001) The current status of pistachio pests in Iran. J Econ Entomol 56:315-322

Mehrnejad MR (2010) Potential biological control agents of the common pistachio psylla, Agonoscena pistaciae, a review. Entomofauna 31(21):317-340

Pilkington LJ, Hoddle MS (2006) Use of life table statistics and degree-day values to predict the invasion success of Gonatocerus ashmeadi (Hymenoptera: Mymaridae), an egg parasitoid of Homalodisca coagulate (Hemiptera: Cicadellidae) in California. Biol Control 37:276-283

Pourali Z, Kheradmand K, Mehrnejad MR, Ghajarieh H (2010) Development and thermal requirement of Anthocoris minki pistaciae (Hemiptera: Anthocoridae) at different temperatures. Acta Entomol Sin 53(4):474-478

Rajabi GR (2004) Insect ecology, 2nd edn. Ministry of Jihad-e-Agriculture, Agricultural Research and Education Organization, Tehran, p 622

Sigsgaard L, Esbjerg P, Philipsen H (2006) Experimental releases of Anthocoris nemoralis F. and Anthocoris nemorum (L.) (Heteroptera: Anthocoridae) against the pear psyllid Cacopsylla pyri L. (Homoptera: Psyllidae) in pear. Biol Control 39(1):87-95. https://doi.org/10.1016/j.biocontrol.2006.02.008

Simonsen MLR, Enkegaard A, Bang CN, Sigsgaard L (2009) Temperature effect on the predation rate of Anthocoris nemorum (Heteroptera: Anthocoridae) on cabbage aphids (Homoptera: Aphididae). J Appl Entomol 133(3):198-200

Souliotis C, Markoyiannaki Printziou D, Lefkaditis F (2002) The problems and prospects of integrated control of Agonoscena pistaciae (Homoptera: Sternorrhyncha) in Greece. J Appl Entomol 126:384-388. https://doi.org/10. 1046/j.1439-0418.2002.00678.x

Yanik E, Ugur A (2004) Consumption of Cacopsylla pyri (L.) (Homoptera: Psyllidae) and Ephestia kuehniella Zell. (Lepidoptera: Pyralidae) eggs by predator Anthocoris nemoralis (F.) (Heteroptera: Anthocoridae) under laboratory and natural conditions. Plant Prot Bull 44:47-67

Yanik $E_{\text {, Unlu } L}$ (2010) The effects of different temperatures and relative humidity on the development, mortality and nymphal predation of Anthocoris minki. Phytoparasitica 38(4):327-335

Yanik E, Unlu L (2011) Biological traits and prey consumption of Anthocoris minki fed on Agonoscena pistaciae and Brachycaudus amygdalinus (Thuleaphis). Phytoparasitica 39(4):333-342. https://doi.org/10.1007/s12600-011-0165-5 
Zhang SC, Zhu F, Zheng XL, Lei C, Zhou XM (2012) Survival and developmental characteristics of the predatory bug Orius similis (Hemiptera: Anthocoridae) fed on Tetranychus cinnabarinus (Acari: Tetranychidae) at three constant temperatures. Eur J Entomol 109:503-508

Zohdi H (2016) Molecular detection of pistachio psylla in the gut contents of ladybirds in pistachio orchards and determination of the role of alternative hosts on the efficacy and interaction of dominant ladybirds with Agonoscena pistaciae. Ph.D. Thesis, University of Guilan, Guilan, p 195

Zohdi H, Hosseini R, Sahragard A, Mohammadi AH (2015) Molecular detection of common pistachio psylla (Agonoscena pistaciae Burckhardt and Lauterer) in the gut contents of Oenopia conglobata beetles. J Entomol Zool Stud 3:77-83

\section{Submit your manuscript to a SpringerOpen ${ }^{\circ}$ journal and benefit from:}

- Convenient online submission

- Rigorous peer review

- Open access: articles freely available online

High visibility within the field

- Retaining the copyright to your article

Submit your next manuscript at $\boldsymbol{\nabla}$ springeropen.com 